\title{
DO VIDEOS USED DURING LECTURES HELP FIRST YEAR MBBS STUDENTS GAIN \& RETAIN KNOWLEDGE IN ANATOMY BETTER?
}

\section{Suman Tiwari}

Associate Professor, MVJ Medical College \& Research Hospital, Bangalore, India.

\section{ABSTRACT}

Background: Video clips used during lectures reinforce the information taught verbally thus improving the overall learning experience of students. The present study has been done to compare the immediate and long term post test MCQ scores of students taught Gross Anatomy using lectures with videos and without videos.

Material and methods: One forty four $1^{\text {st }}$ year MBBS students -were divided into two groups A \& B (72 in each group) by Random Sampling. Topic 1 (Venous drainage of lower limb), was chosen and Group A was exposed to lectures with videos and Group B to lectures without videos. An immediate post test on venous drainage of lower limb was done comprising of 10 MCQ. After Cross over, Topic 2 (Knee Joint) was chosen and Group A was exposed to lectures without videos and Group B to lectures with videos. An immediate post test on knee joint was done comprising of $10 \mathrm{MCQ}$. After 1 month, to test the long term retention of knowledge gained, post test was given for both the topics which comprised of the same set of MCQ.

Results: The Mean \pm SD for the immediate post test MCQ scores were $6.15 \pm 1.87$ (Group A) \& 4.85 \pm 2.30 (Group B) for Topic1, 2.26 \pm 1.25 (Group A) \& 4.04 \pm 1.76 (Group B) for Topic 2. The long term post test MCQ scores were

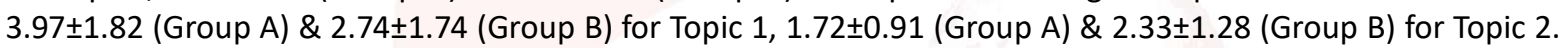

Conclusion: Lectures with videos are more effective when compared to lectures alone as the knowledge gained and retained by the students in Anatomy was better when traditional lectures are combined with videos.

Key words: Anatomy, Lectures, Videos.

Corresponding Author: Dr. Suman Tiwari, Associate Professor, Department of Anatomy, MVJ Medical College \& Research Hospital, Hosakote, Bangalore-562114, Karnataka, India. E-Mail:sumanravi80@gmail.com

Access this Article online

Quick Response code

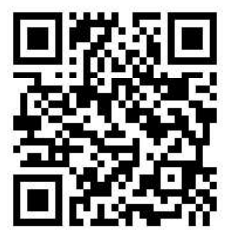

DOI: $10.16965 /$ ijar.2019.261

Journal Information

\section{International Journal of Anatomy and Research}

ICV for 2016 ISSN (E) 2321-4287 | ISSN (P) 2321-8967

90.30 https://www.ijmhr.org/ijar.htm DOI-Prefix: https://dx.doi.org/10.16965/ijar

\section{Article Information}

Received: 22 Jun 2019

Peer Review: 24 Jun 2019

Revised: None
Accepted: 05 Aug 2019

Published (O): 05 Oct 2019

Published (P): 05 Oct 2019

\section{INTRODUCTION}

Anatomy as a subject in $1^{\text {st }}$ year MBBS curriculum has vast portions and many subdivisions. Traditional methods of teaching Anatomy are facing challenges. With the introduction of new Competency based medical curriculum, it is essential that the present day medical educators incorporate innovative teaching learning methods in their classroom. To make Anatomy learning more effective and to retain the knowledge gained, it is required to sustain the interest of students and make them feel more engaged during routine lectures. This can be achieved by reinforcing the traditional lectures with videos. Incorporating videos with traditional didactic lectures not only improves their attention \& concentration levels, but also enhances the satisfaction of the students and keeps them motivated during the entire learning process.

Video assisted lecture has a potential for improving the quality of medical education [1]. Video clips used during lectures help the students in better understanding of complex concepts. They reinforce the information which 
has been taught verbally thus improving their overall learning experience $[2,3]$.

The present study has been undertaken to compare the immediate and long term post test MCQ scores of students exposed to lectures with videos and lectures without videos.The effectiveness of this combined method (lectures with videos) on the knowledge gained \& retained of students in Gross Anatomy would be analysed.

\section{MATERIALS AND METHODS}

The present study was done on 144 first year MBBS students in the Department of Anatomy, MVJ Medical College \& Research Hospital, Bangalore. The type of study was Interventional Quantitative Cross over study. After obtaining ethical clearance from the Institutional Ethical Committee, $1441^{\text {st }}$ year MBBS students were divided into two groups $A$ \& $B$ (72 in each group) by Random Sampling. Topic 1 (Venous drainage of lower limb) was chosen and the duration of the topic was 2 hrs. Group A (72 students) underwent lectures with videos and Group B (72 students) lectures without videos. Three videos namely Overview of lower limb veins, Deep vein thrombosis, Diagnosis \& treatment of varicose veins were shown to Group A for a total duration of $30 \mathrm{~min}$. An immediate post test on venous drainage of the lower limb was done comprising of $10 \mathrm{MCQ}$. After doing cross over,
Topic 2 (Knee Joint) was chosen and the duration of the topic was 2 hrs. Group A (72 students) underwent lectures without videos and Group B (72 students) lectures with videos. Three videos namely Anatomy of Knee Joint, Injuries to the Knee joint and posterior drawer test were shown to Group B for a total duration of $30 \mathrm{~min}$. An immediate post test on Knee Joint was done comprising of $10 \mathrm{MCQ}$. After 1 month, to test the long term retention of knowledge gained, post test was done which comprised of the same set of MCQ. The MCQ test conducted were case based \& comprised of ten single response Multiple choice questions. The questions compiled not only tested higher order of cognitive domain but also required multilogical thinking.

Statistical analysis: The data obtained was analysed by Independent sample t test and the two groups (Group A \& B) were compared.

\section{RESULTS}

The immediate and long term post test MCQ scores of both the groups (Group A \& Group B) have been compared and summarized in Table $1 \&$ Table 2. The values of the $t$ test for Group $A$ \& Group B $(p<0.0001)$ explains that both knowledge gained and retained was better in the group which received intervention in the form of videos.

Table 1: Comparison of immediate post test MCQ scores of Group A \& Group B for Topic 1 (Venous drainage of lower limb) \& Topic 2 (Knee Joint)

\begin{tabular}{|c|c|c|c|c|}
\hline & \multicolumn{2}{|c|}{ Topic 1 (Venous drainage of lower limb) } & \multicolumn{2}{c|}{ Topic 2 (Knee Joint) } \\
\hline & $\begin{array}{c}\text { Group A } \\
\text { (Lecture with videos) }\end{array}$ & $\begin{array}{c}\text { Group B } \\
\text { (Lecture without videos) }\end{array}$ & $\begin{array}{c}\text { Group A } \\
\text { (Lecture without videos) }\end{array}$ & $\begin{array}{c}\text { Group B } \\
\text { (Lecture with videos) }\end{array}$ \\
\hline Mean \pm SD & $6.15 \pm 1.87$ & $4.85 \pm 2.30$ & $2.26 \pm 1.25$ & $4.04 \pm 1.76$ \\
\hline P Value & \multicolumn{2}{|c|}{$<0.0001$} & & $<0.0001$ \\
\hline
\end{tabular}

Table 2: Comparison of Long term post test MCQ scores of Group A \& Group B for Topic 1 (Venous drainage of lower limb) \& Topic 2 (Knee Joint)

\begin{tabular}{|c|c|c|c|c|}
\hline & \multicolumn{2}{|c|}{ Topic 1 (Venous drainage of lower limb) } & \multicolumn{2}{c|}{ Topic 2 (Knee Joint) } \\
\hline & $\begin{array}{c}\text { Group A } \\
\text { (Lecture with videos) }\end{array}$ & $\begin{array}{c}\text { Group B } \\
\text { (Lecture without videos) }\end{array}$ & $\begin{array}{c}\text { Group A } \\
\text { (Lecture without videos) }\end{array}$ & $\begin{array}{c}\text { Group B } \\
\text { (Lecture with videos) }\end{array}$ \\
\hline Mean \pm SD & $3.97 \pm 1.82$ & $2.74 \pm 1.74$ & $1.72 \pm 0.91$ & $2.33 \pm 1.28$ \\
\hline P Value & \multicolumn{2}{|c|}{$<0.0001$} & \multicolumn{2}{c|}{$<0.0001$} \\
\hline
\end{tabular}

\section{DISCUSSION}

A study done by Sayed [1] on 27 nursing students revealed that video-based lectures were more successful with reduced failures as compared with the traditional method of teaching Anatomy but these differences were not 
statistically significant. Moreover, the student's acceptance and satisfaction with the video based lectures was much higher. Video assisted lectures are more useful as they focus the students attention and help them to internalise the information. With videos, the learners are provided with multisensory experience as they link audio \& visual together. It also allows the students to view actual objects and realistic scenes leading to enhanced motivation during the learning process. The knowledge is conveyed in a more interesting way; thus the learners can easily understand and recall the content.

Viswasom [2] conducted a study on 94 MBBS students to compare the effectiveness of video demonstration over conventional methods of teaching osteology in Anatomy. The students were able to identify bony features better with clear visualisation and three dimensional view when taught using the video demonstration method. They concluded that the ideal method would be to incorporate newer multimedia techniques into traditional classes.

A study was done by Smyrni [3] to evaluate the impact of video based vs traditional lectures on students' learning. The results showed that teaching material based on video clips was at least as equally effective as standard teaching lectures.

A Study conducted on 60 staff nurses to determine the Effectiveness of Video Assisted Teaching Vs Lecture Method on knowledge regarding immediate management of Patients with Myocardial Infarction revealed that video assisted teaching gives more knowledge than the lecture method [4].

The present study showed that there was a statistically significant difference between the mean scores of the two groups favoring lectures with videos as a more effective teaching method compared to lectures alone. The knowledge gained and retained by the students in Anatomy was better when traditional lectures are combined with videos which is in agreement with the previous studies [1-4].

However, the present study could have been done by choosing more topics and obtaining feedback from the students.

Video supported lectures can be prepared economically and used easily. In traditional lectures, there may be synchronization problem and disjunction between figures \& words leading to reduced comprehension. In video clips, the visual and auditory information are synchronized which leads to increased comprehension [5].

Traditional lectures have the limitations depending on the lecturers' skills, inability of repetition of the lecture, and limited educational material usage. Video assisted lectures offer several benefits such as the provision of rich educational materials, the superior demonstration of subtle details during procedures, the ability of repetition, and the ending with standardization in medical education.

In Medical Education Video assisted learning is a strong tool and teachers should incorporate it to explain complex procedures and ideas to students. Incorporating videos alongside lectures can shift the concept of teaching from didactic approaches to constructivist learning [6]. Videos used along with lectures provide authentic learning opportunities to the students and enables the learners to acquire research and organizational skills, Colloborative working and problem solving. They also improve self directed learning ability of students due to intellectual curiosity and willingness to learn for them selves [7].

\section{CONCLUSION}

The results of the present study showed that lectures with videos are a more effective teaching method compared to lectures alone. The knowledge gained and retained by the students in Anatomy was better when traditional lectures are combined with videos Hence it would be recommended to incorporate blended learning methods into traditional classes This study further supports the competency based undergraduate medical education curriculum in which early clinical exposure was introduced alongside basic \& clinical sciences to enrich learning.

\section{ACKNOWLEDGEMENTS}

I sincerely thank the mentors of St John's Medical College, Bangalore and ACME team for their guidance \& support while carrying out this research project. 


\section{Conflicts of Interests: None}

\section{REFERENCES}

[1]. Sayed R, Sayed S. Video-based lectures: An emerging paradigm for teaching human anatomy and physiology to student nurses. Alexandria Journal of Medicine 2013; 49: 215-222.

[2]. Viswasom A, Jobby A. Effectiveness of Video Demonstration over Conventional Methods in Teaching Osteology in Anatomy. Journal of Clinical and Diagnostic Research. 2017; 11(2): JC09-JC11.

[3]. Smyrni P, Nikopoulos C. Evaluating the impact of video based vs. traditional lectures on students learning. Educational Research. 2010; 1(8): 304311.

[4]. Sarika A. A Study to Determine the Effectiveness of Video Assisted Teaching Vs Lecture Method on Knowledge of Staff nurses Regarding Immediate Management of Patients with Myocardial Infarction, at a Selected Hospital, in Visakhapatnam District. International Journal of Science \& Research. 2018; 7 (5):1611-1615.
[5]. Sanhan A, Oray NC, Gullupinar B, Yanturali S. The comparison of the efficiency of traditional lectures to video supported lectures within the training of the Emergency Medicine residents. Turkish Journal of Emergency Medicine.2016; 16: 107-111.

[6]. Tayade A, Tayade S, Chalak A, Srivastava T. The impact of Video Assisted learning (VAL) on slow learners. International Journal of Biomedical and Advance Research. 2018; 9(1): 13-18.

[7]. Park HR, Park EH. Video-aided and Traditional Learning Method: A Comparison Regarding Students' Knowledge Retention. Indian Journal of Science and Technology. 2016; 9(40): 1-6.

\footnotetext{
How to cite this article:

Suman Tiwari DO VIDEOS USED DURING LECTURES HELP FIRST YEAR MBBS STUDENTS GAIN \& RETAIN KNOWLEDGE IN ANATOMY BETTER?. Int J Anat Res 2019;7(4.1):6992-6995. DOI: 10.16965/ijar.2019.261
} 